fit for their former employment, 30 fit for light work, 7 unfit for any work, 6 found to be unsuitable for rehabilitation, 20 referred back to hospitals and 5 left before completion of treatment. There seems to be little doubt from the enthusiasm of patients that this centre meets a real need and is in fact a valuable complement to existing health services.

D. S.

\section{THE PRINCIPLES AND PRACTICE OF INDUSTRIAL MEDICINE}

Edited by Fred. J. Wampler, M.D.

(The Williams and Wilkins Co., Baltimore. 1943. Pp. 579. 33s.)

This book covers the field of industrial medicine in the U.S.A. in a series of chapters or monographs written by thirty-three different contributors.

Chapters are devoted to the appraisal and control of industrial health hazards, industrial accidents, the layout of the factory medical department, the effects of temperature and humidity, lighting, fatigue and the commoner occupational diseases including dermatitis. There are sections on physical examinations in industry, venereal disease control, on what industry can do to improve nutrition, the care and prevention of eye injuries, traumatic shock and burns, the industrial back, and the nurse in industry.

In addition vocational and industrial rehabilitation is discussed, and there are chapters on compensation, occupation and tuberculosis, women in industry, and industrial medical services for the smaller plant.

D. S.

\section{OUTLINES OF INDUSTRIAL MEDICINE, LEGISLATION AND HYGIENE}

James Burnet, M.D.

(John Wright \& Sons, Bristol. 1943. Pp. 87. 7s. 6d.)

The author states that this short book does not presume to be a treatise on the subject with which it deals. $\mathrm{He}$ intends it to be solely an introduction to further studies in this branch of medicine.

The book is divided into three parts. Part I deals briefly with industrial diseases, covering the subject in less than fifty short pages. Part II covers industrial legislation such as the Workmen's Compensation Acts and the Factories Act. Part III consists of six pages dealing with industrial hygiene.

D. $\mathrm{S}$.

\section{A STUDY OF ABSENTEEISM AMONG WOMEN} Industrial Health Research Board Emergency Report No. 4

(H.M. Stationery Office. 1943. Pp. 12. 2d.)

This investigation was undertaken by the Industrial Health Research Board at the request of the Ministry of Supply. It is a short-term inquiry concerned with the amount and distribution of absenteeism amongst women, rather than with its causes. The Board states: 'Despite the restricted scope of the investigation, the results are considered sufficiently interesting to merit publication, and it is hoped that the work may serve as a guide to similar investigations in other war factories.'

The main conclusions are as follows. Absenteeism was not regularly recurrent, for example each week, but was as varied as the individual needs and desires of the women concerned. Married women tended to have more longer and fewer shorter absences than single women. Absenteeism on the morning shift was higher than on the afternoon and night shifts. (The two factories investigated were on the three-shift system.) It varied on different days of the week, being highest on Saturday and low on pay-day. Women up to 25 years of age lost more time than older age groups. The results suggest that attempts to reduce absenteeism should be directed to single shift and to full week absences, the latter being due mainly to sickness.

\section{MANUAL OF INDUSTRIAL HYGIENE}

Edited by Wm. M. Gafafer, D.Sc.

W. M. Saunders \& Co., Philadelphia and London. 1943. Pp. 508. 18s.)

This book is the combined effort of sixteen authors, all of them experienced in this branch of medicine in the U.S.A. It is divided into three main parts-organization and operation of facilities; prevention and control of disease in industry; and the manpower problem.

The first part consists of chapters devoted to the organization of health services in industry, referring specially to war conditions. It includes sections on nursing and dental services. An interesting part is that devoted to a description of the available services in industrial medicine and hygiene in the U.S.A.

Part II is the longest section of the book and is devoted in the main to occupational diseases, medical control of respiratory diseases and venereal disease, industrial psychiatry, health education, the causes and control of industrial fatigue, and nutrition in industry. Chapters are also devoted to plant sanitation, and the problems of heating, lighting and ventilation are discussed at some length.

Part III is devoted to information on the maximum use of manpower, referring specially to war-time conditions, to the problems of women in industry, and to the causes and prevention of absenteeism.

D. S.

\section{SUMMARY REPORT BY THE DEPARTMENT \\ OF HEALTH FOR SCOTLAND}

(H.M. Stationery Office. Cmd. 6462. 1943. Pp. 20. 4d.)

This is the third war-time summary prepared in place of the usual fuller annual reports of peace-time by the Department of Health for Scotland. It covers the activities and interests of the department for the year ended June 30, 1943.

The standard of health in Scotland remains at a satisfactory level. Reasons given are the efficient health services built up since the last war; the nutritional basis of the food rationing and other schemes of the Ministry of Food; the ready availability of employment; and the increased purchasing power of the working classes. The mild weather of the winter of $1942-3$ was also a contributing factor.

The incidence of pulmonary tuberculosis, however, continues to increase. Measures taken to check this disease include the allocation of more hospital beds; arrangements for miniature mass radiography; and the provision of money allowances to encourage patients to undertake treatment at an early stage.

Substantial progress has been made in the development of plans in the spheres of housing, health, social services and town and country planning. Meanwhile such limited opportunities as are available in war-time are being taken to improve housing conditions and to maintain progress in the development of health measures. D. $\mathrm{S}$. 